\title{
EAl Endorsed Transactions

\section{Capacity Enhancement and Voltage Stability Improvement of Power Transmission Line by Series Compensation}

\author{
Md. Raihan-Al-Masud ${ }^{1, *}$, Md. Minarul Islam ${ }^{2}$, Md. Shahriar Hasan ${ }^{3}$ and Prajoy Podder ${ }^{4}$ \\ ${ }^{1}$ B.Sc. in Electrical and Electronic Engineering, raihan.emasud@ gmail.com \\ ${ }^{2}$ Department of Electrical and Electronic Engineering, University of Dhaka, minarbuet@gmail.com \\ ${ }^{3}$ B.Sc. in Electrical and Electronic Engineering, shahriarhasaneee@ gmail.com \\ ${ }^{4}$ B.Sc. in Electronics and Communication Engineering, prajoypodder@gmail.com
}

\section{Abstract}

To install a new infrastructure of a power transmission line is not only costly but also time-consuming, and it also have some harmful impact on our environment and therefore existing transmission infrastructure is important to use effectively. FACTS is a popular solution to utilize this existing power transmission system by using series compensation by means of the series capacitor to enhance the power transmission capacity as well as voltage stability. This paper explores the utilization of series capacitor applying to the power grid of Eastern part of Bangladesh. For doing this we have considered the analytical calculation of $10 \%$ to $85 \%$ compensation of that power line. As a result, we have observed that the power transfer capacity has been enhanced about 37 times and it also improve the voltage stability, when the compensation ration is $85 \%$. We consider our calculation mathematically and represent the load curve and voltage profile by plotting in Matlab.

Keywords: power Transmission line, Reactive power, Series compensation, FACTS, voltage stability, Grid investment.

Received on 13 September 2018, accepted on 19 December 2018, published on 21 March 2019

Copyright () 2019 Md. Raihan-Al-Masud et al., licensed to EAI. This is an open access article distributed under the terms of the Creative Commons Attribution licence (http://creativecommons.org/licenses/by/3.0/), which permits unlimited use, distribution and reproduction in any medium so long as the original work is properly cited.

doi: 10.4108/eai.13-7-2018.157034

"Corresponding author. Email: raihan.emasud@ gmail.com

\section{Introduction}

The demand for electricity is increasing due to the fast growth of industries, household, and many others. Therefore need to generate more power and transmit that bulk power from a region to another region to full fill the demand of electricity. As a result, when the existing transmission line has limitation to transmit more extra power, need to install new transmission infrastructure from a region to another region. Then, It is necessary to improve the maximum limit of power transfer of an existing power transmission system to overcome the challenges related to constructing new transmission infrastructure.[18] The Power transmission capability can be improved directly by using series compensation [17].
Due to the thermal limit, A transmission line is possible to load up, however, practically if there do not compensate reactive elements, the voltage of that transmission line can drop out below the limit by quality criteria [16].

The main purpose of Flexible AC transmission system (FACTS) technology is to keep a system under control and to transmit more power from one place to another place. System stability also increases by FACTS. Series FACTS devices especially series capacitor (SC) has been used successfully in many years to improve load ability of high voltage (HV) transmission networks. The principle is to reduce the positive reactance of the transmission line by inserting negative reactance to enhance the transfer capability. 
In a steady-state situation, the main interest is to use the series compensation for controlling the impedance of transmission lines. Series compensation is introduced to the power system to enhance the level of power transfer capability in transmission lines. Using series compensation, the objective of the work is to explore the performance of the power system by introducing a series capacitor into the system. The result of the performance will figure out and compared to determine the effectiveness of series compensation's application in power system.

There are many compensation techniques in the literature. The compensation technique using a series capacitor is broadly used throughout the world[12]. Figure 1 shows a series compensated transmission system in Texas, USA. They applied for $70 \%$ compensation by using fixed series capacitors[12].

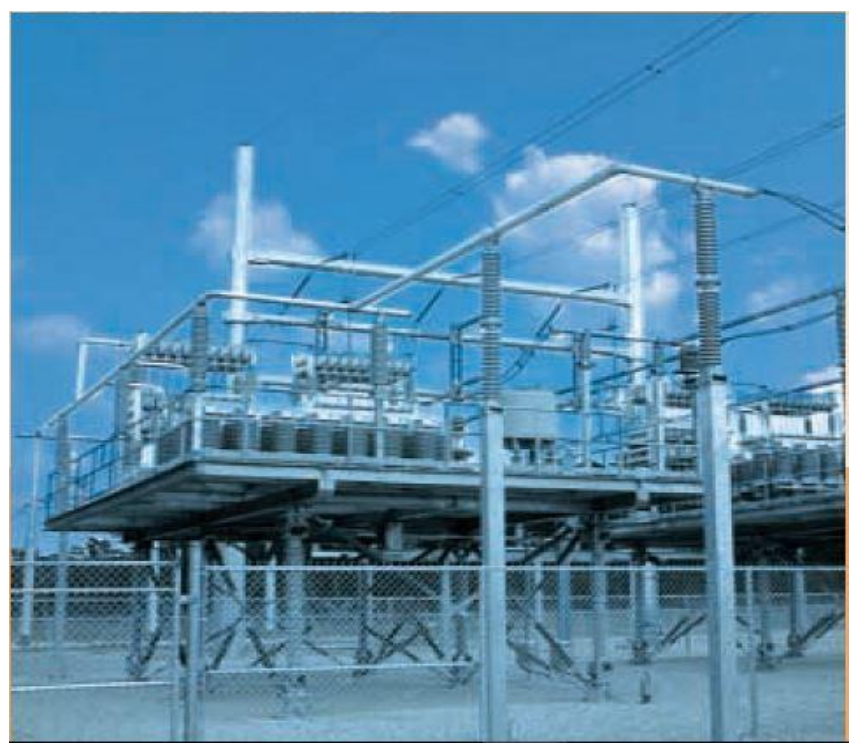

Figure 1. Series Capacitor compensation (70\%) in the USA.

Paper [1] discussed the application of series-shunt compensation. TCSC and SVC, which are two members of FACTS devices, used to improve power transmission capability of EWIs (East-West Interconnectors) (from Ghorasal to Ishurdi) of Bangladesh Power Transmission System. $71.8 \%$ of capacity has been enhanced after compensating the transmission line. In paper [2], it has been focused on using series compensation on a specific area in Canada, Hydro-Quebec, long distribution line. The study was done on $60 \mathrm{~km}$ distribution system supplying industrial and household customers. Three levels of compensation had been tested, $0 \%$ (non-compensated), $36 \%$ and $60 \%$. This paper shows that the series compensation improves the power transmission capability as well as the transient and steady-state stability of the voltage profile. In paper [3], a technique of power transfer capability improvement of power transmission line using
SVC has been examined. In that paper, increase in real power flow and progress in a bus voltage profile are noticed after using the SVC. It is noticed that the bus voltage profiles of the network are also improved. In paper [4], the uses of series compensation in the transmission system and shunt reactors has been presented. The paper gives focus on design and also the implementation of series compensation to solve the problem of working with reactive power and voltage collapse in transmission lines by simulation methods. In paper [5], the author discussed series compensation in which a synchronous source is used to implement series compensation. To compensate for the transmission line, this paper show focuses on Static synchronous series compensator(SSSC). In paper [6], the author did a work on the south-Eastern part of Romanian power grid (Dobrogea - a peninsular area), to increase the transfer capacity to the rest of the grid. The situation considered the present topology and also future developments of the transmission network. Paper [7] works with AC power transmission system and shows the benefits of using FACTS devices on it. The overall process for this system studies and analysis with FACTS installation projects and the paper also discussed the necessity of FACTS devices. Here have an introduction to the elemental circuits of different types of FACTS devices with a focus on system performance characteristics. The reactance value of the transmission and distribution system changes with Series compensation; however, shunt compensation give variation to the corresponding load impedance.

In this paper, we calculate the series compensation (from $10 \%$ to $85 \%$ ) by means of a series capacitor to enhance power capacity and voltage profile of the north-eastern part (from Sylhet to Ashuganj, 132KV overhead power transmission line) in Bangladesh.

\section{Our working area in Bangladesh}

The length in a kilometer of the transmission line from Ashuganj to Sylhet is $170 \mathrm{~km}$, double conductor transmission line as shown in Figure 2. According to the BPDB plans, the establishment of new power plant (of capacity almost $600 \mathrm{MW}$ ) in Sylhet region, therefore there will be huge power generation in Sylhet area. To carry the power from Sylhet to other parts of Bangladesh, BPDB has also planned two new transmission lines as shown in figure 2. But establishing a new power transmission line may not be the best solution, because, establishing a new transmission line is so expensive and also takes a longer time to build it up. In this situation compensation of transmission line is the best way to transmit more power with the existing transmission line. In this situation, compensation from Sylhet to Ashuganj $132 \mathrm{KV}$ line will be the best solution up to a certain limit of carrying power. Because compensating an existing transmission line by $70 \%$ its real power carrying capacity can be enhanced more than twice of its uncompensated line. So it 
is our proposal to compensate for the transmission line (Sylhet to Ashuganj, 132KV overhear line) using series compensation technique which will be economical to carry more power without establishing a new transmission line.

In this paper, Different compensation ratio will be calculated to see the enhancement of maximum transmitted power and voltage stability.

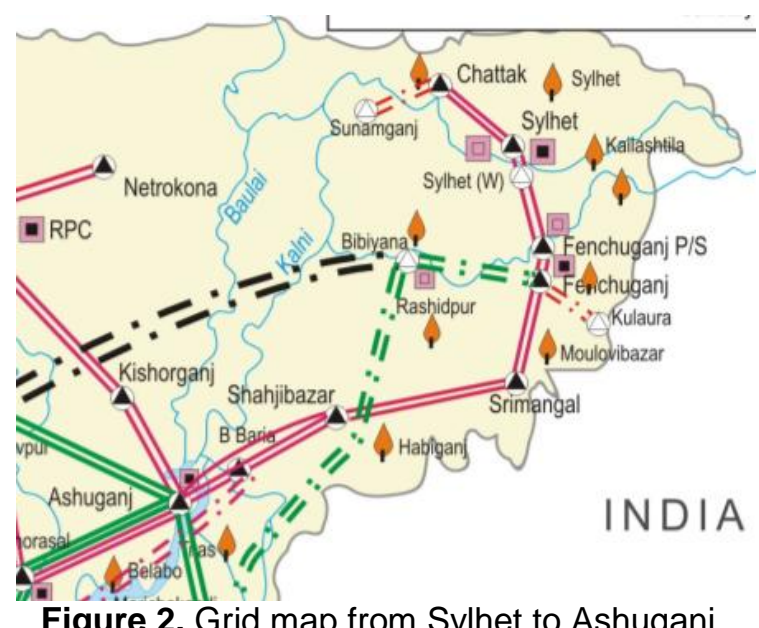

LEGEND

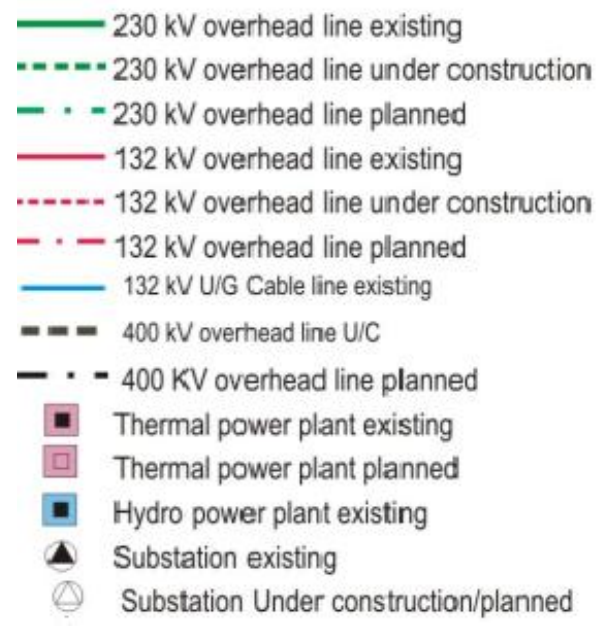

\section{Compensation of Power Transmission Line}

The demand for electricity is increasing day by day in every country. So we try to establish a new power plant to meet the electricity demand. But it has a problem that not only power plant but also required to establish a new power transmission line if the existing transmission line has low capacity to transmit power. But there are a lot of negative effects of establishing a new power transmission line. To establish a new power line is very costly and time-consuming. It has also a great effect on the environment. It wastes a large area of land and it is also harmful to people and their resident area.

Compensation in transmission lines is basically reducing the inductive or capacitive effects of a transmission line. As we already know, an inductor has positive impedance whereas a capacitor has a negative impedance. Thus if a transmission line is predominantly inductive, capacitors are used in series or parallel so as to negate the inductive impedance. Conversely, if the line is predominantly capacitive, then inductors are used in series to cancel the capacitive effects. This summarizes transmission line compensation.

When we inject the negative reactance in a power transmission line, it will improve the voltage regulation profile by preventing power line from extreme voltage drop, whereas the positive reactance injection in a power transmission line improves transmission efficiency. Both synchronous compensation and static compensation are available to perform this work. Synchronous compensation and Static compensation associated with synchronous phase modifier and capacitors respectively. Therefore, by compensating the existing transmission line we can effectively transfer more power and it also increases the voltage stability and also angle stability.

\subsection{Types of Compensation}

There are a lot of methods which are efficiently using throughout the world. They can be classified into three categories such as

- shunt compensation

- series and shunt combinational compensation

- series compensation

Generally, they are classified into two main groups: series and shunt compensation.

\subsection{FACTS Devices as a compensation Technique}

FACTS stands for flexible AC transmission systems. Properly utilized, this offers benefits to users of a variety of kinds. Without the need of build up a new grid by means of improving the existing lines and substations, FACTS accomplish with enhancing system stability and availability, power transmission capability, power quality, load sharing between parallel circuits, improving voltage stability in the grid, Reduce environmental impact, transmission losses etc[15]. This is why the FACTS is coming in.

\subsection{Technology related to the FACTS}

- Series Capacitors (SC) 
- SVC

- Controllable series compensation

- STATCOM etc

\section{Series Compensation(Series Capacitors (SC))}

For a long power transmission line, the ratio of reactance to resistance is very high. There is possible to introduce different types of series compensation. Series capacitor as a series compensation is one of the solutions of that problem. If a series capacitor introduces to the transmission line, the ratio of reactance to resistance could be reduced. As a result, there will flow more real power in the transmission line and give a low voltage drop.

The series capacitor is not quite simple in the transmission line. It requires proper protection, control, and supervision to facilities its performance as a part of the rest of the power system. It also needs to be insulated from ground. To protect a capacitor mainly used a varistor. This varistor is mainly $\mathrm{ZnO}$ (Zinc-oxide) type [13]. It limits the voltage which is across the capacitor to keep in a save value in the junction in a fault condition because it raises the current in a short circuit condition through the transmission line. During the fault condition, the varistor cannot absorb excess fault current. Therefore, there is a spark gap in most of the cases which enable the by-pass of the capacitor in that situation. High power plasma switch, spark gap and power electronic device, etc. are all different types of solution of the bypass. At last, a circuit breaker also needs to be introduced if the bypass enables for a long time. The circuit breaker also helpful when the spark gap is not present or to extinguish the spark.

\section{The principal of Compensation in Power Transmission System}

In a power system has some variable by which we can control the system. The power-angle curve is very popular about controlling power in a stable situation. The curve is static although by implementing the FACTS devices we can get a dynamic solution of the power-angle curve. Primarily, there is three main variable by which it is possible to control the power system. These are Voltage, Angle and Impedance[7].

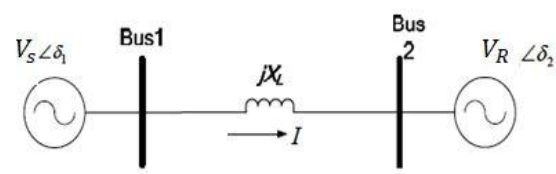

(a)

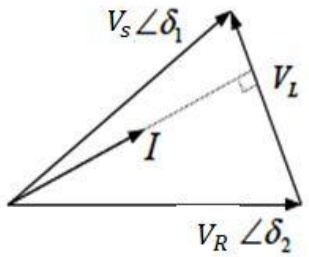

(b)

Figure 3. Power transmission system (a) simplified model (b) phase diagram.

Figure 3(a) shows a typical model of a power system where two power grid are connected with each other. The reactance of this line is $\mathrm{X}_{\mathrm{L}} \cdot \mathrm{V}_{\mathrm{S}} \angle \delta 1$ and $\mathrm{V}_{\mathrm{R}} \angle \delta 2$ are representing the sending end and receiving end voltage respectively[15][14]. The current represented by I. There are two power grid busses and the angle between buses is $\delta=\delta 1-\delta 2$. The phasor diagram of this typical transmission line representing in $3(\mathrm{~b})$. The reactive power $\left(\mathrm{Q}_{\mathrm{S}}\right)$ and active power $\left(\mathrm{P}_{\mathrm{S}}\right)$ at bus 1 can be written as

$$
\begin{aligned}
P_{S} & =\frac{V_{S} V_{R} \operatorname{Sin} \delta}{X_{L}} \\
Q_{S} & =\frac{V_{S}\left(V_{S}-V_{R} \operatorname{Cos} \delta\right)}{X_{L}}
\end{aligned}
$$

Where,

$V_{S}=$ Sending end voltage $(\mathrm{V})$

$V_{R}==$ Receiving end voltage $(\mathrm{V})$

$\delta=$ phase angle between $\mathrm{V}_{\mathrm{s}}$ and $\mathrm{V}_{\mathrm{R}}$.

$X_{L}=$ Series inductive reactance $(\Omega)$

The reactive and active power at bus 2 can be written as

$$
\begin{aligned}
P_{R} & =\frac{V_{S} V_{R} \operatorname{Sin} \delta}{X_{L}} \\
Q_{R} & =\frac{V_{R}\left(V_{R}-V_{S} \operatorname{Cos} \delta\right)}{X_{L}}
\end{aligned}
$$

From equations (1) to equations (4) we can easily observe that the real and reactive power is possible to regulate by controlling phase angle, voltage and line impedance of a power transmission system. It is well known that the active power flow will reach the maximum when the phase angle $\delta$ is $90^{\circ}$. In reality, a small angle is maintained for the stability purpose from the dynamic oscillation and transient situation.

For capacitive compensation, if the reactance is $\mathrm{X}_{\mathrm{C}}$ then the reactance of the line become $\left(X_{L}-X_{C}\right)$ from $X_{L}$. In this case from eq (3), the power can be expressed as 


$$
P_{C}=\frac{V_{S} V_{R} \sin \delta}{X_{L}-X_{C}}
$$

Now, from equations (3) and equations (5), the ratio of power transmission between compensated and uncompensated lines can be expressed as

$$
\frac{P_{c}}{P_{R}}=\frac{X_{L}}{X_{L}-X_{C}}=\frac{1}{1-\frac{X_{L}}{X_{C}}}=\frac{1}{1-k}
$$

Where,

$$
k=\frac{X_{C}}{X_{L}}
$$

The factor $\mathrm{K}$ is the degree of compensation [11] (also known as compensation factor). The series capacitive reactance equal to $X_{C}$ and the inductive reactance of the line equal to $X_{L}$

\subsection{Effect on voltage profile:}

If we can reduce the inductive reactance, then it is also possible to get a power system with a low voltage drop (Rajesh Rajaraman et.al., 1998). When a load is connected with lagging power factor, the voltage in that line is

$$
V_{d}=I\left(R \cos \Phi+X_{L} \sin \Phi\right) V
$$

When a capacitor by means of negative reactance $X_{C}$ is induced in a power system, then it minimizes the positive reactance of the power system to $\mathrm{X}_{\mathrm{L}}-\mathrm{X}_{\mathrm{C}}$ and it also reduces the voltage drop[10][19]. Furthermore, the reactive power gets reduced in the power system.[8] Figure 4 gives the equivalent circuit and its phasor diagram.

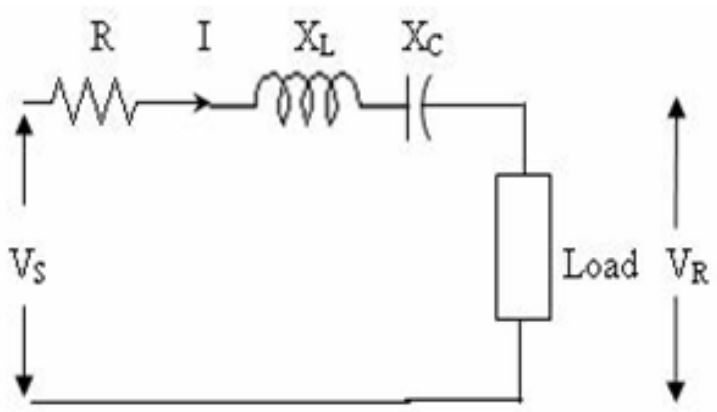

(a)

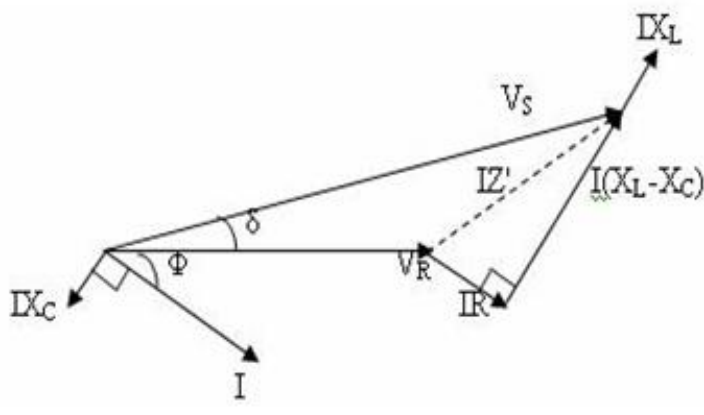

(b)

Figure 4. series compensated transmission line (a) single line diagram (b)phasor diagram.

It can be observed from the phasor diagram that line voltage drop is

$$
V_{d}=I\left(R \cos \Phi+\left(X_{L}-X_{C}\right) \sin \Phi\right) V .
$$

Thus it is possible to reduce voltage drop by introducing series capacitor even if there is a low power factor at the receiving end. There is possible to introduce switching technique to control the voltage if the load is in variable condition. The high voltage could damage the capacitor if there occur any short circuit fault, so there need high protection for the series capacitor. The capacitor we use for compensation can introduce a few problems such as Ferro-resonance, Sub-synchronous resonance, and high recovery voltage.

\subsection{Capacity enhancement and stability study after compensation}

When assuming a lossless line, the power-angle relationship[9] can be written as:

$$
P_{R}=\frac{V_{S} V_{R}}{Z_{C} \sin \theta} \sin \delta .
$$

where $\theta=\beta 1$ is the electrical length(without compensation) of the line (Here, $\beta$ is phase constant ) and is the angle by which $\mathrm{V}_{\mathrm{S}}$ leads $\mathrm{V}_{\mathrm{R}}, \delta$ is the load angle and $\mathrm{Z}_{\mathrm{c}}=$ Characteristic impedance(without compensation).

A lossless transmission line is loaded to its SIL(surge impedance loading) and if $\mathrm{V}_{\mathrm{S}}=\mathrm{V}_{\mathrm{R}}=$ rated voltage, then the natural load is

$$
P_{O}=\frac{V_{S} V_{R}}{Z_{C}}
$$

Now, Equation (7) can be rewritten as Equation (9): 


$$
P_{R}=\frac{P_{O}}{\sin \theta} \sin \delta
$$

The equation is applicable for asynchronous and also for the synchronous load at the receiving end.

Figure. 5(a) shows the $\delta-\mathrm{P}_{\mathrm{R}} / \mathrm{P}_{\mathrm{O}}$ relationship [9] for a transmission line. In comparison, the $\mathrm{V}_{\mathrm{m}}-\mathrm{P}_{\mathrm{R}} / \mathrm{P}_{\mathrm{O}}$ curve [9] of the line is shown in Figure 5(b).

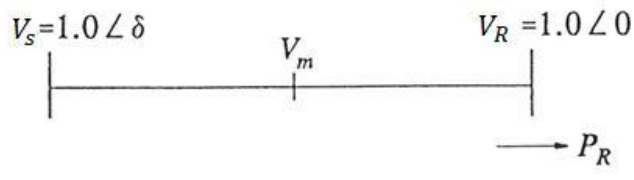

(a)

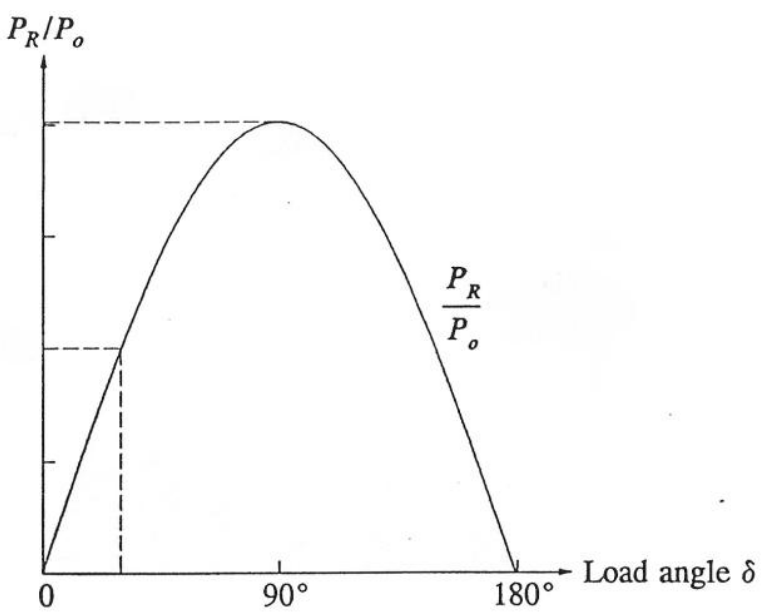

(b)

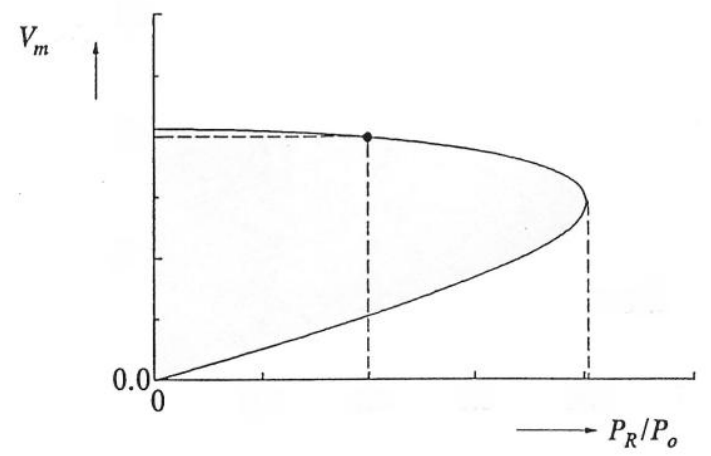

(c)

Figure 5. (a)Transmission line (b) $\mathrm{P}_{\mathrm{R}}-\delta$ characteristics. (c) $V_{m}-P_{R}$ transmission characteristics.

When reactance has changed [9] of a transmission line then we can write

$$
P_{R}=\frac{V_{S} V_{R}}{Z_{C}^{\prime} \sin \theta^{\prime}} \sin \delta
$$

$$
\begin{aligned}
& \frac{P_{R}}{P_{O}}=\frac{Z c}{Z^{\prime} c} \frac{\sin \delta}{\sin \theta^{\prime}} . \\
& v_{m}=\frac{P_{R}}{P_{O}} \frac{Z^{\prime} c}{Z c} \frac{\sin \left(\theta^{\prime} / 2\right)}{\sin (\delta / 2)} .
\end{aligned}
$$

Here,

$Z^{\prime}{ }_{C}=$ Characteristic impedance(with compensation)

$\theta^{\prime}=$ line angle(with compensation)

$V_{m}=$ Midpoint Voltage

$\frac{P_{R}}{P_{O}}=$ Power Transfer Ratio

Due to the change of $Z c$ and $\theta$, the maximum power transfer capability will also change.

\section{Analytical And Graphical Presentation}

We analyze with $132 \mathrm{KV}$ high voltage transmission line from Sylhet to Ashuganj. The grid network from Sylhet to Ashuganj is shown in figure 6 .

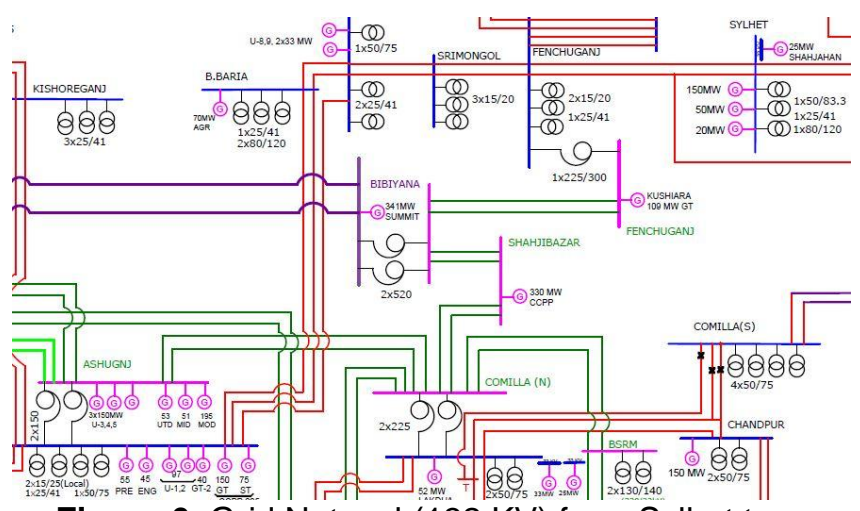

Figure 6. Grid Network(132 KV) from Sylhet to Ashugonj.

The length of the line which is supposed to be compensated is $170 \mathrm{~km}$. So, length, $1=170.1 \mathrm{~km}$.

In this paper, we have considered the transmission line (from Sylhet to Ashugnj) is supplying power to distribution network which is composed of mostly inductive load.

\subsection{Line Angle Calculation}

In Bangladesh power line frequency is $50 \mathrm{~Hz}$ and transmission line length from Sylhet to Ashugonj is $170 \mathrm{~km}$.

We know, the velocity of propagation:

$v=f^{*} \lambda$ 
So, Wavelength, $\lambda=\mathrm{v} / \mathrm{f}$

$=3 * 10^{8} / 50 \mathrm{~m}$ [let velocity of propagation $\mathrm{v}=3 * 10^{8}$ $m / s]$

$$
=6 * 10^{6} \mathrm{~m}=6^{*} 10^{3} \mathrm{~km} \text {. }
$$

Again, phase constant, $\beta=2 * \mathrm{pi} / \lambda=1.04719 * 10^{-03} \mathrm{rad} / \mathrm{km}$ $=.001047 \mathrm{rad} / \mathrm{km}$.

We also know, Line Angle, $\theta=\beta l=[(.001047) * 170] \mathrm{rad}$ $=0.178 \mathrm{rad}=10.233^{\circ}$ (for only $50 \mathrm{~Hz}$ ).

So the line angle $(\theta)$ of this line is $10.233^{\circ}$.

\subsection{Zc ( Surge Impedance / Characteristic Impedance) Calculation}

According to the PGCB(Power Grid Company Bangladesh), the positive sequence reactance from Sylhet to Ashugonj $(170 \mathrm{~km})$ is $0.37518 \mathrm{pu}$, and the Susceptance of this line is $0.0885 \mathrm{pu}$. The $\mathrm{Z}_{\text {base }}=174.24 \Omega$ and $\mathrm{Y}_{\text {base }}$ $=5.7392 * 10^{-3}$ Siemens.

So, the value of reactance is $64.62 \Omega$. Now we can calculate the inductance (L) of this line which is $2.056 * 10-4 \mathrm{H} / \mathrm{m}$ and the Susceptance value of the line, $\mathrm{B}=$ $5.079192 * 10-4$. So, the capacitance (C) of this line is $1.6166 * 10-9 \mathrm{~F} / \mathrm{m}$

Therefore, characteristic impedance $\mathrm{Zc}=\sqrt{ }(\mathrm{L} / \mathrm{C})=356.62$ $\Omega$

\subsection{Representation Tool}

For getting the Graphical view, we have used MATLAB. We write code according to the equation of power transmission and midpoint voltage. We write code for compensating from $10 \%$ to $85 \%$ of the power transmission line from Sylhet to Ashugonj.

\section{Simulation Result}

Using the values of line angle ( $\theta$ ) and characteristic impedance $(\mathrm{Zc})$, we will calculate the maximum power transfer capability and voltage profile of that power line. The output from the calculation will be explained in the following sections.

\subsection{Without Compensation}

At first, we calculate an uncompensated line. The results obtained from the calculation are in the following:

$\mathrm{Z}_{\mathrm{c}}=356.62 \Omega$

$\theta=10.233^{\circ}$

From equation (9) we can write:

$$
\begin{aligned}
\frac{P_{R}}{P_{O}}= & \frac{1}{\sin \theta} \sin \delta \\
& \left.=\sin \delta / \sin \left(10.233^{\circ}\right)\right) \\
& =5.628 * \sin (\delta)
\end{aligned}
$$

Also considering one half of the symmetrical line, $\mathrm{P}$ may be expressed in terms of $\mathrm{V}_{\mathrm{m}}$ as:

$$
P_{R}=\frac{V_{S} V_{m}}{Z_{C} \sin (\theta / 2)} \sin (\delta / 2) .
$$

From this equation(14) we can express $\mathrm{V}_{\mathrm{m}}[9]$ as:

$$
\begin{aligned}
v_{m}= & \frac{P_{R}}{P_{O}} \frac{\sin (\theta / 2)}{\sin (\delta / 2)} \\
& =0.5017 *(\sin \delta / \sin (\delta / 2))
\end{aligned}
$$

Using equation(13) and equation(15) we can get figure 7 and figure 8 respectively. The graphical representation ('load curve' and 'P-V curve') for without compensation is in below

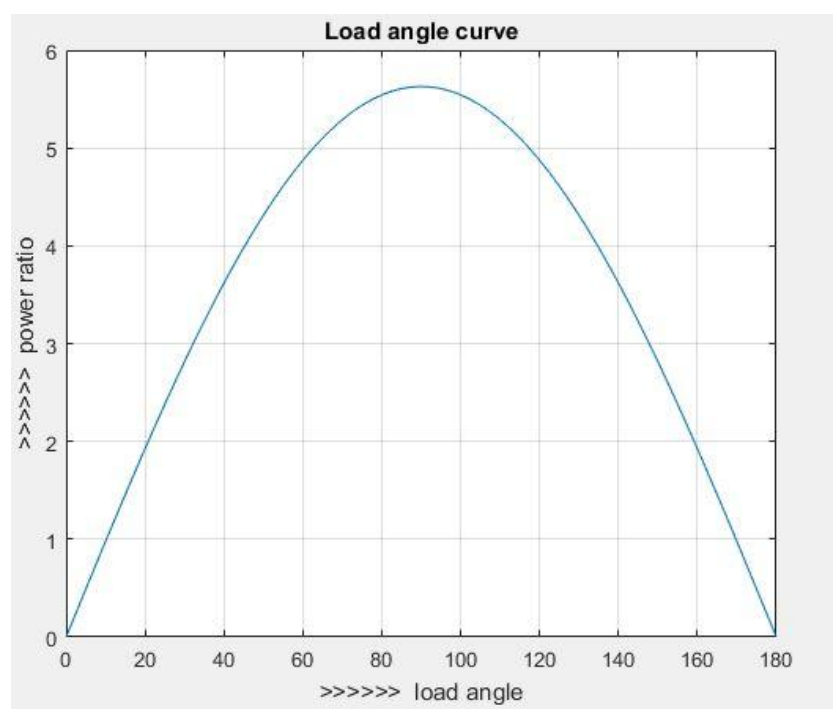

Figure 7. $P_{R} / P_{0}-\delta$ characteristics for without compensation. 


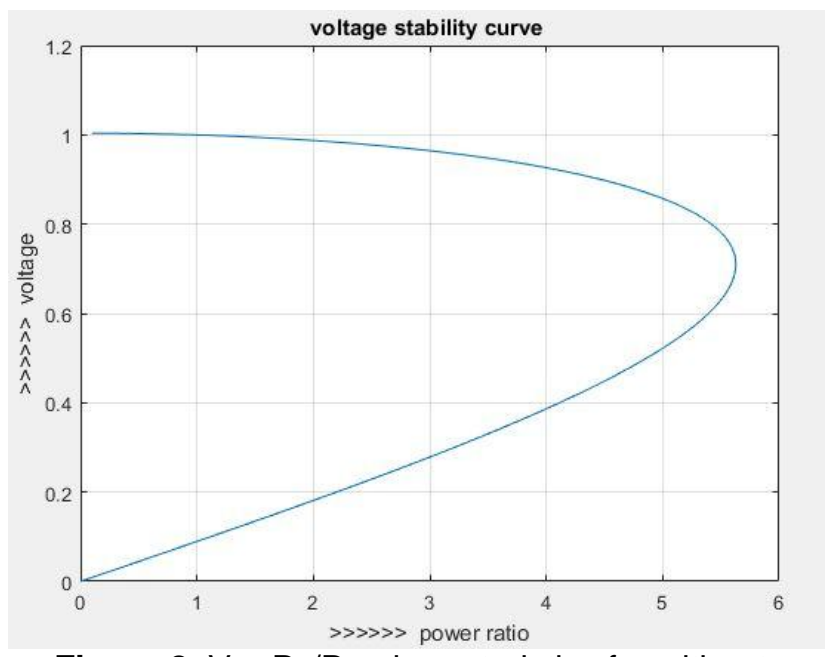

Figure 8. $V_{m}-P_{R} / P_{o}$ characteristics for without compensation.

\subsection{For $10 \%$ Compensation}

Using equation (1.10), we get:

$$
k_{s e}=\frac{x_{C s e}}{x_{L}}=0.1
$$

Now changed impedance and angle will be [9]

$$
\begin{aligned}
& Z^{\prime} c=Z c / \sqrt{1-k_{s e}}=356.62 * \sqrt{ }(1-0.1)=338.32 \Omega \\
& \theta^{\prime}=\theta \sqrt{1-k_{s e}}=10.233 * \sqrt{ }(1-0.1)=9.7078^{\circ}
\end{aligned}
$$

Now from equation (11), we get:

$$
\frac{P}{P_{O}}=\frac{Z c}{Z^{\prime} c} \frac{\sin \delta}{\sin \theta^{\prime}}=6.25^{*} \sin (\delta)
$$

And from equation(12) we get:

$$
v_{m}=\frac{P}{P_{O}} \frac{Z^{\prime} c}{Z c} \frac{\sin \left(\theta^{\prime} / 2\right)}{\sin (\delta / 2)}=
$$

\begin{tabular}{|c|c|c|c|}
\hline $\begin{array}{l}\text { Compensatio } \\
\text { n Ratio } \\
\text { ( K ) }\end{array}$ & $\begin{array}{l}\text { Changed } \\
\text { impedance } \\
\left(\mathbf{Z c}^{\prime}\right)\end{array}$ & $\begin{array}{l}\text { Changed } \\
\text { line Angle } \\
\left(\theta^{\prime}\right)\end{array}$ & $\begin{array}{l}\text { Changed } \\
\text { Maximu } \\
\text { m Power } \\
( \\
\left.\mathbf{P}_{\mathbf{R}} / \mathbf{P}_{\mathbf{o}}\right) \mathbf{m a} \\
\mathbf{x} \\
\text { (pu) }\end{array}$ \\
\hline $\begin{array}{l}\text { No } \\
\text { compensation }\end{array}$ & $356.62 \Omega$ & $10.233 .66^{\circ}$ & 5.628 \\
\hline $\begin{array}{l}0.1 \quad(10 \% \\
\text { compensation })\end{array}$ & $338.32 \Omega$ & $9.7078^{\circ}$ & 6.25 \\
\hline $\begin{array}{l}0.2 \quad(20 \% \\
\text { compensation) }\end{array}$ & $318.97 \Omega$ & $9.1526^{\circ}$ & 7.0287 \\
\hline $\begin{array}{l}0.3 \quad(30 \% \\
\text { compensation) }\end{array}$ & $298.36 \Omega$ & $8.5615^{\circ}$ & 8.0286 \\
\hline $\begin{array}{l}0.4 \quad(40 \% \\
\text { compensation })\end{array}$ & $276.23 \Omega$ & $7.9264^{\circ}$ & 9.3617 \\
\hline $\begin{array}{l}0.5 \quad(50 \% \\
\text { compensation) }\end{array}$ & $252.16 \Omega$ & $7.2358^{\circ}$ & 11.228 \\
\hline $\begin{array}{l}0.6 \quad(60 \% \\
\text { compensation })\end{array}$ & $225.54 \Omega$ & $6.4719^{\circ}$ & 14.0276 \\
\hline $\begin{array}{l}0.7 \quad(70 \% \\
\text { compensation) }\end{array}$ & $195.32 \Omega$ & $5.6048^{\circ}$ & 18.6941 \\
\hline $\begin{array}{l}0.8 \quad(80 \% \\
\text { compensation) }\end{array}$ & $159.48 \Omega$ & $4.5763^{\circ}$ & 28.0255 \\
\hline $\begin{array}{l}0.85 \quad(85 \% \\
\text { compensation })\end{array}$ & $138.118 \Omega$ & 3.962 & 37.3688 \\
\hline
\end{tabular}

$0.5017 *(\sin \delta / \sin (\delta / 2))$
Similarly, A table of without compensation and also $10 \%$ to $85 \%$ compensation is in below

Table 1. Compensation profile

Using equation (11) and equation (12) the graphical representation ('load curve' and 'P-V curve') from $10 \%$ to $85 \%$ compensation is in figure 9 and figure 10 . 


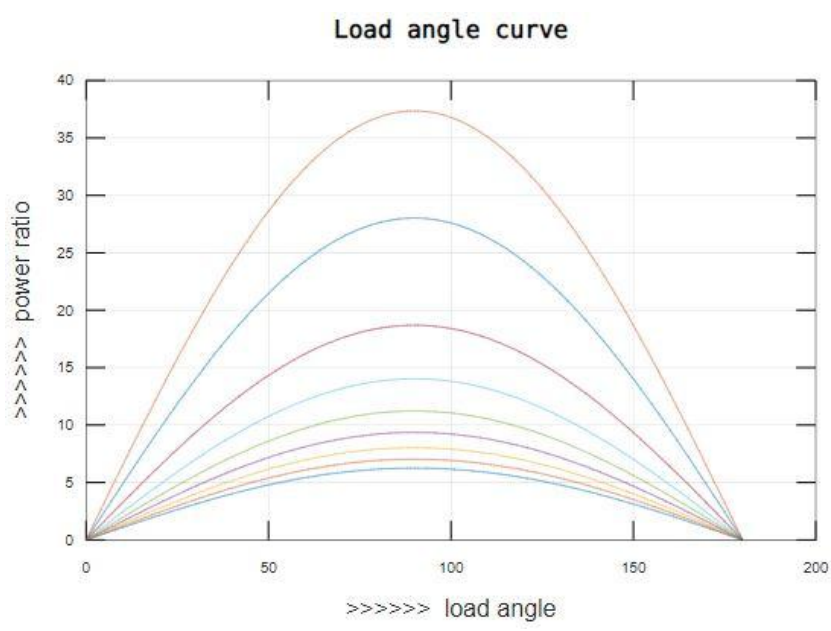

Figure 9. $P_{R} / P_{0}-\delta$ characteristics for $10 \%$ to $85 \%$ compensation.

Figure (9) shows that it is possible to increase the maximum power transfer capability by applying for compensation. The maximum power transfer ratio for compensation from $10 \%$ to $85 \%$ shown in table 1 .

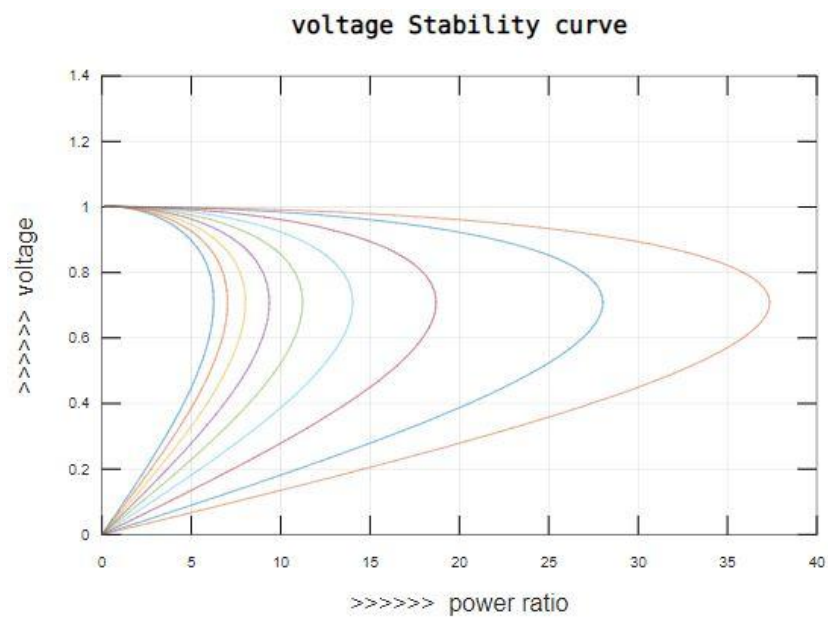

Figure 10. $V_{m}-P_{R} / P_{o}$ characteristics for $10 \%$ to $85 \%$ compensation.

The above figure shows that if we increase the compensation ratio from Sylhet to Ashugonj, then not only increase maximum power capacity but also improve the voltage profile with stability by reducing collapse voltage.

\section{Conclusion}

From the above analytical and graphical presentation, we can say that reducing reactance in series of transmission line, the maximum power transfer capability increases and also improves voltage profile and dynamic stability. Generally, $30 \%$ - $85 \%$ compensation does for power transmission. In contrast, overcompensation increases ferroresonance phenomenon. Due to avoiding Subsynchronous resonance, ferroresonance and high recovery voltage, the compensation ration require less than $100 \%$, which means the $X_{c}$ require less than $X_{L}$. Ferroresonance is harmful for power transmission line because it generates over voltage and heavy currents that damages the components of power system. Subsynchronous resonance can cause possible failure or damage of the generator involved such as shaft fatigue. In addition, when the compensation ratio is high specially when it is more than $80 \%$, it increases the secondary arc current, which increases the complexity of the secondary arc extinguishment [20]. Here, Power can't be transferred more than the sub-station installed capacity. In this paper, we consider only transmission line which is supplying power to the distribution network and the distribution networks mainly contain the inductive load.

\section{References}

[1] M. Shafiul Alam, Md. Abdur Razzak, Md. Nazmul Hasan, A. Hasib Chowdhury (2012)"Transmission Capacity Enhancement of East-West Interconnectors Using SeriesShunt Compensation" in 2012 7th International Conference on Electrical and Computer Engineering, 2022 December, Dhaka, Bangladesh.

[2] R. Wamkeue, N. Kandill, J. East, Y.Boisclair, "Series Compensation for a Hydro -Quebec Long Distribution Line" Rouyn-Noranda, QC, J9X 5E4, Canada

[3] Md. Nazmus Sahadat, Nahid-Al-Masood, Md. Shakhawat Hossain, Gilmanur Rashid, A. Hasib Chowdhury, "Real Power Transfer Capability Enhancement of Transmission Lines Using SVC" Dhaka, Bangladesh

[4] Dr. Hussein Thani Rishag (2012) "Reduction Reactive Power and Collapse Voltage Using Series Capacitors Compensation in Sudden Change Loads of Transmission Lines" in Eng.\&Tech. Journal ,Vol. 30, No.5,

[5] Laszlo Gyugyi, Colin D. Schauder, Kalyan K. sen, (1997) "Statictic Synchronous Series Compensator: A Solid-State Approach To The Series Compensation Of Transmission Lines" in IEEE Transactions On Power Delivery, Vol.12, No. 1,January.

[6] C. Bulac, Member, IEEE, C. Diaconu, M. Eremia, Senior Member, IEEE, B. Otomega, I. Pop, L. Toma, Member, IEEE, I. Tristiu, Member, IEEE (2009) "Power Transfer Capacity Enhancement using SVC" in "2009 IEEE Bucharest Power Tech Conference, June 28th - July 2nd, Bucharest, Romania .

[7] John J. Paserba, Felloe, IEEE "how facts controllers benefit ac transmission systems".

[8] Irinjila Kranti Kiran, Jaya Laxmi.A, (2011)"Shunt versus Series compensation in the improvement of Power system" in international journal of applied engineering research, dindigul, Volume 2, No 1,

[9] P. kundur, Book:name, "Power system stability and control" "Control of Active power and Reactive power", ch- 6,11

[10] K.S Verma, R.P.Payasi,T.N.Shukla,"Effect of Series and Shunt Compensation on Static Voltage Stability", K.N.I.T.Sultanpur(U.P) 228118 India

[11] Rolf Gruenbaum, Jon Rasmussen,(2012) "Series Capacitors for Increased Power Transmission Capability of 
a $500 \mathrm{kV}$ Grid Intertie" in 2012 IEEE Electrical Power and Energy Conference, 978-1-4673-2080-1/12.

[12] Power Transmission and Distribution, flexible ac transmission systems series compensation, Siemens.

[13] Abdullahi Musa Askira1 , J. D. Jiya2 M. Abdulkadir1, (2018) "modelling and simulation of a single phase Series compensation network" in International Journal of Scientific Engineering and Applied Science (IJSEAS) Volume-4, Issue-03, March, ISSN: 2395-3470

[14] Yongan Deng, Reactive Power Compensation of Transmission Lines

[15] P. Asare, T. Diez, A. Galli, E. O'Neill-Carillo, J. Robertson, and R. Zhao,(1994) "An Overview of Flexible AC Transmission Systems", in Purdue University,ECE Technical Reports

[16] C. A. Canizares, On Bifurcations, (1995) "Voltage collapse and load modelling," in IEEE Transactions on Power System, vol. 10, no. 1, pp. 512-522, Feb.

[17] G. N. Kumar, M. S. Kalavathi, (2011) "Reactive power compensation for large disturbance voltage stability using
FACTS controllers," in Proc. ICECT '11, vol. 2, pp 164167

[18] Khizir Mahmud \& A.K.M. Mahmudul Haque (2012)"Power Scenario of Bangladesh and Schemes of Sustainable Optimal Reduction in the Power System Loss" in Global Journal of Researches in Engineering Electrical and Electronics Engineering Volume 12 Issue 9 Version 1.0

[19] Miss. Reshma Tarannum, Mr. Rashmi Singh,(2017), "Reducing Ferranti Effect in Transmission Line using Dynamic Voltage Restorer" in "International Conference on Science and Engineering for Sustainable Development (ICSESD-2017)", ISSN: 2454-1311, Special Issue 1.

[20] Hongshun Liu (Member, IEEE), Jingjing Yang, Liang Ji (Member, IEEE), Zhen Wang, Zhenning Huang, Xiaoshuai Yang, Jiangtao Wang,(2018), "Influence of Hybrid Reactive Power Compensation on the Secondary Arc of Ultra-High-Voltage Transmission Lines (May 2018)" in "IEEE Access", Digital Object Identifier 10.1109/ACCESS.2018.2850812 